\title{
Synthesis of new sulfonate and phosphonate derivatives for cation- independent mannose 6-phosphate receptor targeting
}

\author{
Audrey Jeanjean, ${ }^{a}$ Magali Gary-Bobo, ${ }^{b}$ Philippe Nirdé, ${ }^{b}$ Simon Leiris, ${ }^{a}$ Marcel Garcia,${ }^{b}$ and Alain Morère ${ }^{\mathrm{a}, *}$ \\ a Institut des Biomolécules Max Mousseron (IBMM), UMR 5247, CNRS, Université Montpellier 2 et 1, Montpellier, F- \\ 34296, France. \\ b IRCM, Institut de Recherche en Cancérologie de Montpellier, Montpellier, F 34298 France ; INSERM, Unité 896 , \\ Montpellier, F 34298 France ; Université Montpellier 1, Montpellier, F 34298 France; CRLC Val d'Aurelle Paul Lamarque, \\ Montpellier, F 34298 France.
}

* corresponding author: Institut des Biomolécules Max Mousseron (IBMM) UMR 5247 CNRS - Universités Montpellier 2 et 1, Bâtiment de Recherche Max Mousseron, Ecole Nationale Supérieure de Chimie de Montpellier, 8 Rue de l'Ecole Normale, F-34296 Montpellier cedex 05, France. Tel.: Int +33 4671443 45; fax: Int +33 467144344

E-mail address: alain.morere@univ-montp2.fr

\begin{abstract}
The cation-independent mannose 6-phosphate receptor (CI-M6PR) is essential for the endocytosis of proteins bearing the mannose 6-phosphate (M6P) recognition marker. This study described the synthesis of M6P and M6S analogues presenting greater affinity for CI-M6PR than their natural compounds. Moreover, the finding of their lack of cytotoxicity for human cells and of their increased stability in human serum supports the high potential of these isosteric derivatives in therapies requiring CI-M6PR targeting.
\end{abstract}

Key words: Mannose 6-phosphate analogues; Mannose 6-sulfate analogues; Cation independent mannose 6-phosphate receptor; Binding affinity.

The cation-independent mannose 6-phosphate receptor (CI-M6PR), a transmembrane glycoprotein of $300 \mathrm{kDa}$, plays very important roles in many biological processes ${ }^{1-3}$. The main role of CI-M6PR is transporting and sorting those lysosomal enzymes that contain the mannose 6-phosphate (M6P) recognition marker in their structure from the trans-Golgi network to the lysosomes ${ }^{4}$. CI-M6PR also mediates the endocytosis of extracellular ligands such as insulin-like growth factor II (IGF2) ${ }^{5}$, retinoic acid ${ }^{6}$ and M6P-containing proteins ${ }^{7}$, which differ from lysosomal enzymes and are internalized through CI-M6PR transport, include Granzyme $\mathrm{B}^{8}$; the herpes simplex virus (HSV) ${ }^{9}$; leukemia inhibitory factor (LIF), ${ }^{10,11}$ and partially renin ${ }^{12}$. CI-M6PR also acts on molecules that do not penetrate into cells such as the latent precursor of transforming growth factor-beta (L-TGF $\beta)^{13}$ and on plasminogen/plasmin conversion ${ }^{14,15}$.

The phosphate moiety as well as the hydroxyl groups on the mannopyranosidic ring of M6P contribute to a hydrogenbonding network with two binding sites of CI-M6PR ${ }^{16}$. This ability to recognize two M6P residues allows CI-M6PR to bind lysosomal enzymes with high affinity $\left(\mathrm{Kd}=10^{-9} \mathrm{M}\right){ }^{17}$.

Among the various proteins and lysosomal enzymes bearing the M6P signal, CI-M6PR binds particular lysosomal enzymes with high affinity, such as those of Dictyostelium discoideum, which contains in its structure the phosphodiester Man-P$\mathrm{OCH}_{3}{ }^{18}$ and M6S residues ${ }^{19}$. This flexibility in the binding of various derivatives of mannose, functionalized at the 6position with phosphate or sulfate moieties, led us to study the impact of mannose derivatives, modified at 6-position, on the binding to CI-M6PR. It has been shown that an isosteric phosphonate analogue of M6P binds with high affinity to the receptor ${ }^{20,21}$ while a non-isosteric phosphonate ${ }^{20}$ or $\beta$-hydroxyphosphonates ${ }^{22}$ are not recognized. Moreover, the flexibility of CI-M6PR with regard to the binding of C-6-modified mannose derivatives was confirmed by the biological study of a series of isosteric carboxylate analogues of $\mathrm{M} 6 \mathrm{P}^{23,24,25}$. The aim of the work described herein was to complete these studies with the syntheses of sulfonate and phosphonate analogues of M6P for subsequent use of these derivatives in such fields as healing improvement ${ }^{26}$ or enzyme replacement therapy ${ }^{23}$ which main limiting factor is the instability of enzyme M6P residues. 
Two isosteric sulfonate analogues of M6S were synthesized. The unconjugated one (Scheme 1) was prepared starting from methyl 2,3,4-tri-O-benzyl- $\alpha$-D-mannopyranoside ${ }^{27}$, which was converted to an aldehyde by Swern oxidation followed by a Wittig-Horner reaction using the anion of triethyl phosphonomethanesulfonate ${ }^{28}$. Deprotection of the sulfonate moiety of $\mathbf{1}$ was then performed by an $\mathrm{S}_{\mathrm{N}} 2$ procedure ${ }^{29,30}$ using tetrabutylammonium iodide to lead to $\mathbf{2}$ in $81 \%$ yield. Complete debenzylation and double bond reduction of $\mathbf{2}$ was achieved by catalytic hydrogenation $\left(\mathrm{H}_{2} / \mathrm{Pd} / \mathrm{C}\right)$ to afford the saturated sulfonate 3 .

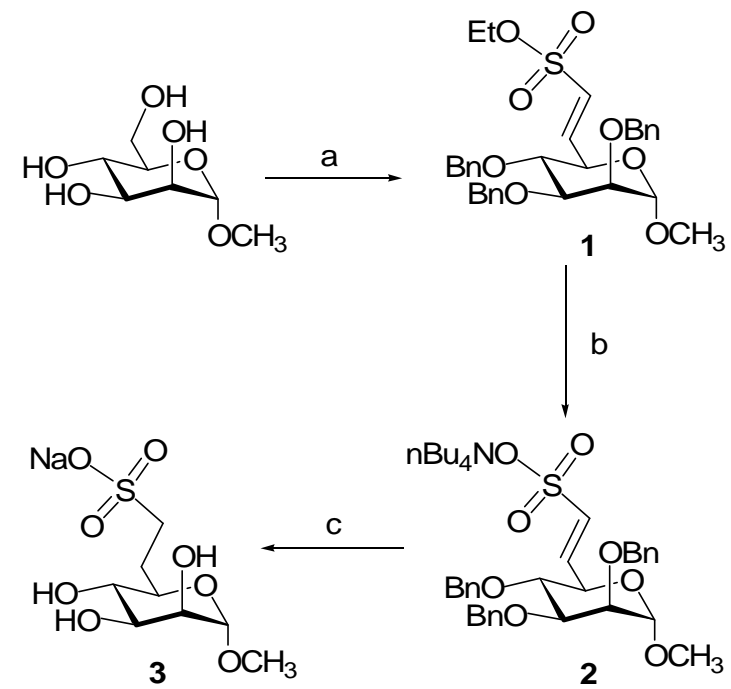

Scheme 1. Reagents and conditions: (a) $\mathrm{i}-(\mathrm{COCl})_{2}, \mathrm{DMSO}, \mathrm{Pr}_{2} \mathrm{NEt},-60^{\circ} \mathrm{C}$; ii-EtO $\mathrm{SCH}_{2} \mathrm{PO}(\mathrm{OEt})_{2}, \mathrm{nBuLi},-68^{\circ} \mathrm{C}, \mathrm{THF}, 55 \%$; $(\mathrm{b}) \mathrm{nBu} \mathrm{NI}_{4}$, acetone, reflux, $15 \mathrm{~h}, 81 \%$; (c) iv-DOWEX Na ${ }^{+}, \mathrm{H}_{2} \mathrm{O} / \mathrm{MeOH}(8 / 2), 1 \mathrm{~h} ; \mathrm{v}-\mathrm{H}_{2} / \mathrm{Pd} / \mathrm{C}, \mathrm{EtOH} / \mathrm{AcOEt}(7 / 3), 4 \mathrm{~h}, 82 \%$.

]

The conjugated sulfonate (Scheme 2) was prepared starting from methyl 2,3,4,6-tetra-O-trimethylsilyl- $\alpha$-Dmannopyranoside ${ }^{31}$, which was directly converted to an aldehyde at 6-position in a one-step procedure ${ }^{32}$. Compound $\mathbf{4}$ was obtained by addition of the triethyl phosphonomethanesulfonate anion to this aldehyde. Deprotection of the sulfonate moiety was performed by treatment with tetrabutylammonium iodide, as described above. Compound $\mathbf{5}$, thus obtained, was converted to the target unsaturated sulfonate $\mathbf{6}$ by a desilylation method using a catalytic amount of ceric ammonium nitrate $(\mathrm{CAN})$ in a mixture of acetonitrile and water $(95 / 5, \mathrm{v} / \mathrm{v})$.

The first step in the preparation of unsaturated phosphonate was performed similarly to 6 (Scheme 2). It consisted of the direct oxidation of methyl 2,3,4,6-tetra-O-trimethylsilyl- $\alpha$-D-mannopyranoside ${ }^{31}$ in aldehyde using the Collins oxidation procedure, followed by the Wittig-Horner reaction using the anion of tetraethyl methylenediphosphonate. The phosphonate $7^{31}$ was then desilylated by treatment with $\mathrm{HCl} 1 \mathrm{M}$ to afford $\mathbf{8}^{31}$ in $95 \%$ yield. The last step was the deprotection of the phosphonate moiety using the classical Rabinowitz procedure ${ }^{33}$. The target unsaturated phosphonate 9 was obtained in $65 \%$ yield.

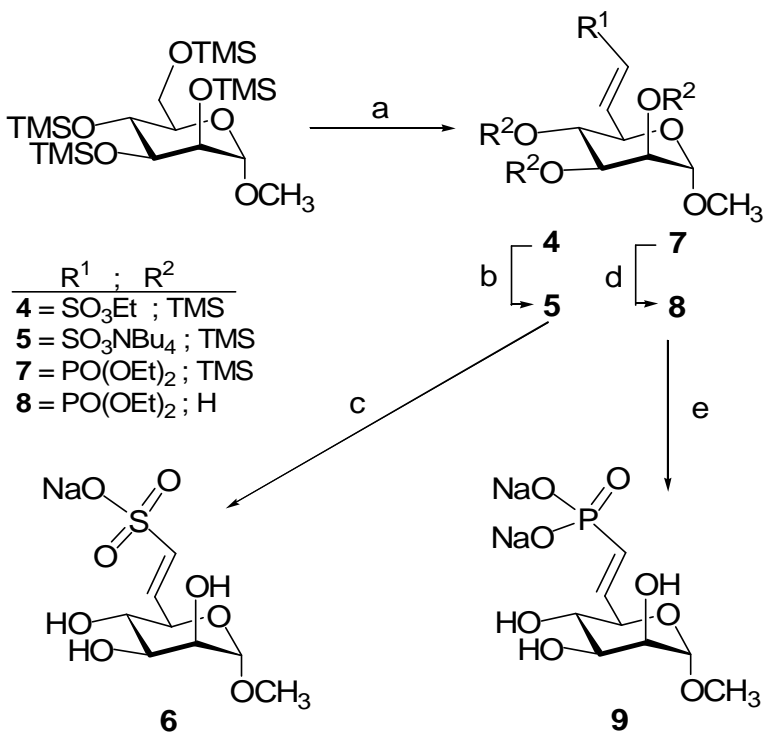


Scheme 2. Reagents and conditions: (a) i- $\mathrm{CrO}_{3} / \mathrm{pyridine}, \mathrm{CH}_{2} \mathrm{Cl}_{2}, 0^{\circ} \mathrm{C}, 1 \mathrm{~h}$; ii-4: $(\mathrm{EtO})_{2} \mathrm{OPCH}_{2} \mathrm{SO}_{3} \mathrm{Et}, \mathrm{nBuLi}, \mathrm{THF},-68^{\circ} \mathrm{C}, 57 \%$; $7:\left((\mathrm{EtO})_{2} \mathrm{OP}\right)_{2} \mathrm{CH} \mathrm{H}_{2}, \mathrm{NaH}$, $\mathrm{THF}, 20^{\circ} \mathrm{C}, 30 \mathrm{~min}, 49 \%$; (b) $\mathrm{nBu}_{4} \mathrm{NI} /$ acetone, reflux, $15 \mathrm{~h}, 95 \%$; (c) $\mathrm{CAN}, \mathrm{CH}_{3} \mathrm{CN} / \mathrm{H}_{2} \mathrm{O}(5 / 5), 2 \mathrm{~h}$ then DOWEX Na ${ }^{+}, 4 \mathrm{~h}, 98 \%$; (d) $\mathrm{HCl} 1 \mathrm{M}, \mathrm{THF}, 20^{\circ} \mathrm{C}$, $10 \mathrm{~min}, 95 \%$; (e) TMSBr, Pyridine, $2 \mathrm{~h}$ then DOWEX Na${ }^{+} 5 \mathrm{~h}, 65 \%$.

The binding affinities of the isosteric analogues of M6P for CI-M6PR were determined using the protocol we recently described ${ }^{24}$. Briefly, increasing concentrations of the analogues were added to the biotinylated CI-M6PR (CI-M6PR $b$ ), which was bound to pentamannose 6-phosphate (PMP) adsorbed on a microtiter plate, in order to displace the receptor from its ligand (PMP). The remaining bound CI-M6PR $b$ was quantified using the streptavidin/peroxidase couple and ophenylenediamine (OPD) substrate by optical density measurements. From these experiments, dose-inhibition curves were drawn (Figure 1) and used to calculate the $\mathrm{IC}_{50}$ values for each isosteric analogue of M6P (Table 1). In a previous paper we demonstrated that M6S shows high affinity for CI-M6PR ${ }^{25}$. Indeed, as it is the case with M6P itself, $2.5 \mathrm{mM}$ of the M6S was demonstrated to be sufficient to displace the CI-M6PR retained on the PMP-sepharose column. This result was confirmed by determination of the binding affinity (Table 1), which was in good agreement with the literature data. Therefore, M6S bound to CI-M6PR 10-fold less well than M6P. Contrary to M6S, the sulfonates were more effectively bound to CI-M6PR. Indeed, unsaturated sulfonate 6 and saturated sulfonate 3 had affinities for CI-M6PR, respectively, $3.2-$ fold and 1.5-fold higher than this of M6S. The finding that compound $\mathbf{6}$ has higher affinity for CI-M6PR than 3 was not surprising. Indeed, we recently reported that the unsaturated carboxylate $\mathrm{M} 6 \mathrm{C}-\mathrm{u}$ displayed 2-fold higher affinity for CIM6PR than the saturated carboxylate $\mathrm{M} 6 \mathrm{C}-\mathrm{s}^{24}$. We assume that in both cases, the unsaturated carboxylate and sulfonate derivatives better matched the binding pocket of CI-M6PR than the saturated analogues. Therefore, in order to complete this study, we extended the comparison to phosphonate derivatives, which are well known to be good bioisosteres of phosphates 34. The binding affinity for CI-

Table 1. Binding affinities for CI-M6PR.

\begin{tabular}{ccc}
\hline Compds. & $\mathrm{IC}^{-5}(\mathrm{M})^{\mathrm{a}}$ & $\mathrm{RBA}^{\mathrm{b}}$ \\
\hline M6P & $2.3 \times 10^{-5}\left( \pm 1.0 \times 10^{-5}\right)$ & 1.0 \\
M6Pn-s $^{20,21}$ & $1.3 \times 10^{-5}\left( \pm 0.2 \times 10^{-5}\right)$ & 1.8 \\
$\mathbf{9}$ & $2.2 \times 10^{-5}\left( \pm 0.3 \times 10^{-5}\right)$ & 1.05 \\
$\mathrm{M}^{25} \mathrm{~S}^{25}$ & $2.3 \times 10^{-4}\left( \pm 0.9 \times 10^{-4}\right)$ & 0.1 \\
$\mathbf{3}$ & $1.5 \times 10^{-4}\left( \pm 0.6 \times 10^{-4}\right)$ & 0.15 \\
$\mathbf{6}$ & $7.1 \times 10^{-5}\left( \pm 1.1 \times 10^{-5}\right)$ & 0.3 \\
\hline
\end{tabular}

${ }^{\mathrm{a}} \mathrm{IC}_{50}$ were obtained from 3 to 5 independent experiments $( \pm \mathrm{SD})$.

${ }^{\mathrm{b}}$ Relative binding affinity $-\mathrm{RBA}^{-} \mathrm{IC}_{50(\mathrm{M} 6 \mathrm{P})} / \mathrm{IC}_{50}$ (Analogue).
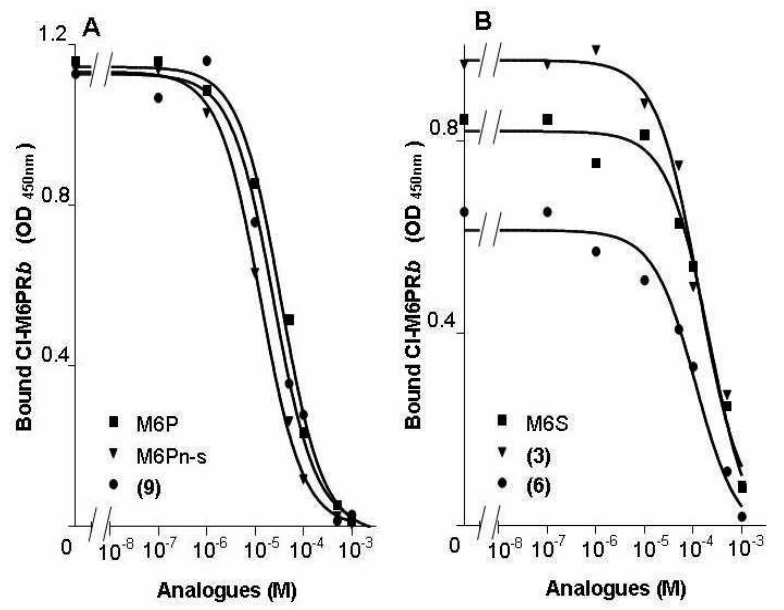

Figure 1 Dose-dependent inhibition of CI-M6PR binding to PMP by M6P analogues.

The binding of CI-M6PR $b$ to PMP was inhibited by increasing concentrations of M6P, saturated (M6Pn-s) or unsaturated (9) M6-phosphonates, M6S or saturated (3) or unsaturated (6) M6-sulfonates. The data represent the mean of triplicates from a typical experiment and were confirmed in two additive experiments.

MбPR of the saturated phosphonate (M6Pn-s) isosteric analogue of M6P was found to be 1.8-fold higher than that of M6P (Table 1) and this result was in very good accordance with the literature data ${ }^{21}$. Surprisingly, the unsaturated phosphonate 9 bound to CI-M6PR less well than the M6Pn-s (Table 1). Indeed, the binding affinity of 9 for CI-M6PR was 2-fold lower than that of M6Pn-s. However, it is noteworthy that the conjugated phosphonate 9 still binds to CI-M6PR as well as M6P 
itself (Table 1). This suggests that, contrary to the sulfonate and carboxylate series, the double bond in 9 leads to a partial inhibitory effect on ligand binding compared with M6Pn-s.

We constructed the analogues based on the X-Ray structure of the M6P (Fig. 2A) liganded into the CI-M6PR (PDB entry 1SZ0). The M6Pn-s displayed more hydrogen bonds with the essential residues in the binding pocket than the M6P counterpart. This better stability of the ligand might explain the better affinity of the phosphonate for the receptor. The phosphonate binding site was composed of six residues that stabilized the ligand (Figure 2B). In contrast, the sulfonate analogue 3 (Figure 2C) was associated with a marked decrease in the binding affinity, and only five residues stabilized this ligand. However, after minimization, moderate orientations of the side chains could have occurred and the direct interaction of residue Y324, which is involved in ligand stability as revealed by single amino acid substitutions ${ }^{35}$, with mannose was missing for this analogue 3. Taken together, these structural parameters might explain the low binding affinity of this analogue for CI-M6PR.

A

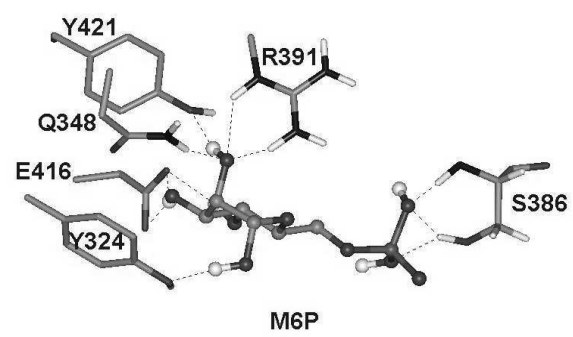

B

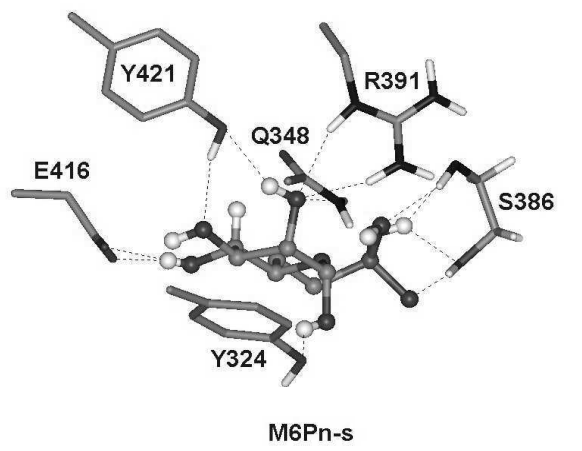

C

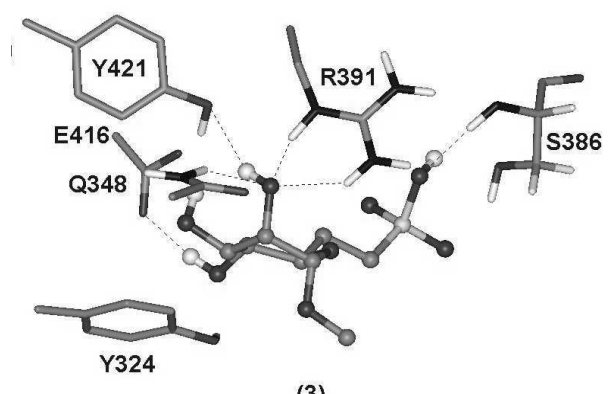

(3)

Figure 2. Ligand docking in the CI-M6PR ligand binding pocket.

(A) Close-up view of M6P taken as a reference ${ }^{16}$. (B, C) Close-up views of the hydrogen bonds between M6Pn-s (B) and 3 (C) and the residues Tyr 421 , Gln 348, Tyr 324, Ser 386 and Arg 391.

Since we previously showed that M6P is unstable in human serum ${ }^{24}$, we compared the stability of the analogues 3, 6 , 9, M6Pn-s and M6S to M6P. After a 2 day-incubation in human serum at $37{ }^{\circ} \mathrm{C}$ the binding capacity of all analogues to CIM6PR was maintained while the affinity of M6P decreased about 5-fold (Figure 3). This indicates that, in contrast to M6P, all the analogues tested were stable after a long exposure in human serum. 


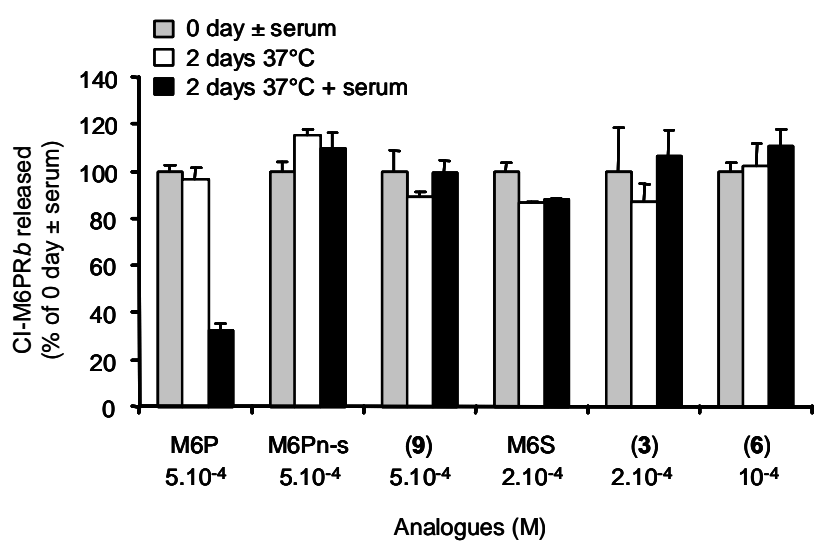

Figure 3. Stability of M6P analogues in human serum.

The competitive inhibition of CI-M6PR $b$ binding to PMP by M6P and its analogues was assayed in the presence or absence of serum ( 0 day \pm serum). These inhibitions were considered as controls and expressed as $100 \%$ (grey). The inhibitions obtained after incubation of M6P and M6P analogues for 2 days at $37^{\circ} \mathrm{C}$ in the absence (white) or presence of $75 \%$ of human serum (black) were compared to the respective controls. Values represent the mean \pm standard deviations of triplicates from a typical experiment and confirmed in two additive experiments.

We also analysed the cytotoxicity of these analogues on human fibroblast cell line and two breast cancer cell lines, MCF7 and MDA-MB-231 (Figure 4 and 5). Increasing concentrations (up to $100 \mu \mathrm{M}$ ) of the compounds 3, 6, 9, M6Pn-s and M6S were incubated for 4 days in culture medium. The growth of all cell lines was unaffected by these compounds indicating that their binding to CI-M6PR, even for a long time period, is neither cytostatic nor cytotoxic. So the replacement of phosphate by a phosphonate or sulfonate group did not cause any toxicity.

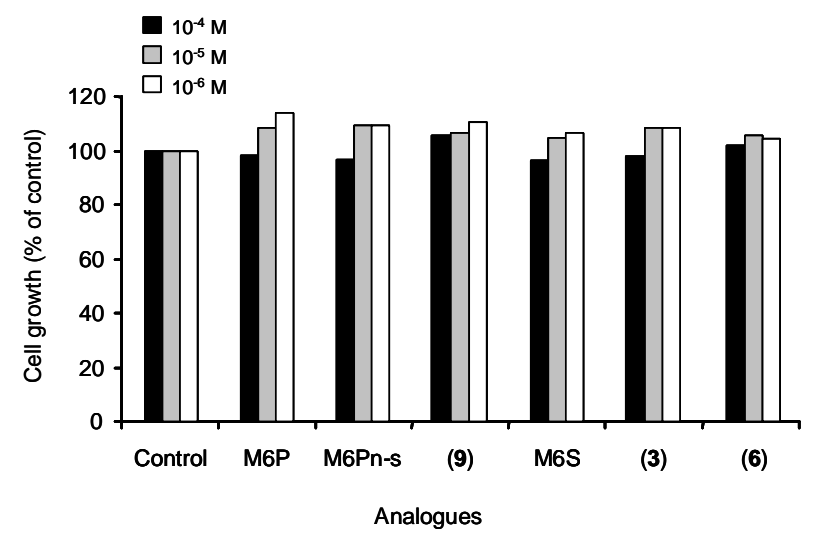

Figure 4. Growth of human fibroblasts in presence of M6P or M6P analogues.

Cells were treated for 4 days in absence (control) or in presence of M6P or M6P analogues as saturated or unsaturated M6-phosphonates or -sulfonates or with M6S. After treatment, cell proliferation was measured by MTT assay as described in the Supporting informations. The data represent a typical experiment and were confirmed in two additive experiments. All standard deviations from triplicate were $\leq 5 \%$.

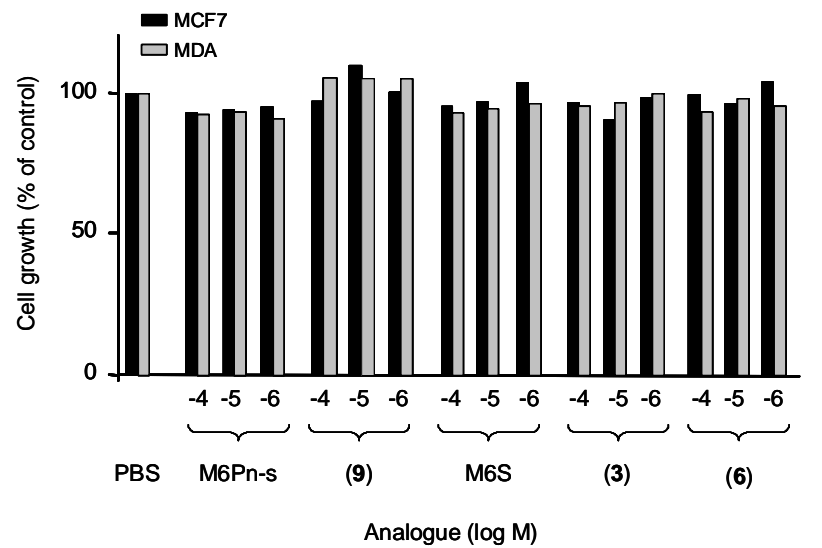

Figure 5. Growth of MCF7 or MDA-MB-231 human breast cancer cell lines in the presence of M6P analogues.

The growth was evaluated in the presence of M6P analogues as described in Figure 3. The data represent a typical experiment and were confirmed in two additive experiments. All standard deviations from triplicate were $\leq 5 \%$. 
In conclusion, chemical modifications on M6P or M6S induced a gain in efficiency resulting in better binding affinity for CI-M6PR and, importantly, greater stability of these compounds in human serum. This study underlines the fact that CI$\mathrm{M} 6 \mathrm{PR}$ can bind a broad range of M6P analogues, and the great diversity of ligands bearing an M6P signal suggests the numerous potential therapeutic applications offered by CI-M6PR. For example, it has already been proposed that exogenous M6P could inhibit the activation of L-TGF- $\beta^{36}$. This prevention of TGF $\beta 1$ and TGF $\beta 2$ activation at the wound site results in markedly improved healing and less scarring ${ }^{37,38}$. This type of competitive inhibition could be applied to other pathological processes that are mediated through CI-M6PR interactions, such as the activation of complex structures in plasminogen activation, growth-regulating proteins (i.e., LIF, Granzyme B) or viral proteins such as HSV glycoprotein D.

\section{Acknowledgements}

We would like to thank Michel Gleizes for technical assitance. We also wish to thank the organisations "Vaincre les Maladies Lysosomales (VML)" for the grant assigned to Magali Gary-Bobo and "Association pour la Recherche sur le Cancer (ARC)" for financial support.

\section{Supplementary data}

Supplementary data associated to this article can be found in the online version at...

\section{References}

1. Dahms, N. M.; Hancock, M. K. Biochim. Biophys. Acta 2002, 1572, 317.

2. Ghosh, P.; Dahms, N. M.; Kornfeld, S. Nat. Rev. Mol. Cell Biol. 2003, 4, 202.

3. Hawkes, C.; Kar, S. Brain Res. Rev. 2004, 44, 117.

4. Kornfeld, S. Annu. Rev. Biochem. 1992, 61, 307.

5. Oka, Y.; Rozek, L. M.; Czech, M. P. J. Biol. Chem. 1985, 260, 9435

6. Kang, J. X.; Li, Y.; Leaf, A. Proc. Natl. Acad. Sci. U S A 1997, 94, 13671.

7. Kornfeld, S.; Mellman, I. Annu. Rev. Cell Biol. 1989, 5, 483.

8. Wowk, M. E.; Trapani, J. A. Microbes Infect 2004, 6, 752.

9. Brunetti, C. R.; Dingwell, K. S.; Wale, C.; Graham, F. L.; Johnson, D. C. J. Virol. 1998, 72, 3330.

10. Blanchard, F.; Raher, S.; Duplomb, L.; Vusio, P.; Pitard, V.; Taupin, J. L.; Moreau, J. F.; Hoflack, B.; Minvielle, S.; Jacques, Y.; Godard, A. J. Biol. Chem. 1998, 273, 20886.

11. Metcalf, D. Stem Cells 2003, 21, 5.

12. Saris, J. J.; van den Eijnden, M. M.; Lamers, J. M.; Saxena, P. R.; Schalekamp, M. A.; Danser, A. H. Hypertension 2002, $39,573$.

13. Yang, L.; Tredget, E. E.; Ghahary, A. Wound Repair Regen. 2000, 8, 538.

14. Godar, S.; Horejsi, V.; Weidle, U. H.; Binder, B. R.; Hansmann, C.; Stockinger, H. Eur. J. Immunol. 1999, $29,1004$.

15. Nykjaer, A.; Christensen, E. I.; Vorum, H.; Hager, H.; Petersen, C. M.; Roigaard, H.; Min, H. Y.; Vilhardt, F.; Moller, L. B.; Kornfeld, S.; Gliemann, J. J. Cell Biol. 1998, 141, 815.

16. Olson, L. J.; Dahms, N. M.; Kim, J. J. J. Biol. Chem. 2004, 279, 34000

17. Tong, P. Y.; Gregory, W.; Kornfeld, S. J. Biol. Chem. 1989, 264, 7962.

18. Gabel, C. A.; Costello, C. E.; Reinhold, V. N.; Kurz, L.; Kornfeld, S. J. Biol. Chem. 1984, 259, 13762.

19. Freeze, H. H. Arch. Biochem. Biophys. 1985, 243, 690

20. Vidil, C.; Morère, A.; Garcia, M.; Barragan, V.; Hamdaoui, B.; Rochefort, H.; Montero, J.-L. Eur. J. Org. Chem. $1999,447$.

21. Berkowitz, D. B.; Maiti, G.; Charette, B. D.; Dreis, C. D.; MacDonald, R. G. Org. Lett. 2004, 6, 4921.

22. C. Vidil C.; S. Vidal, S.; Morère, A.; Garcia, M.; Montero, J.-L. Eur. J. Org. Chem. 2000, 3433.

23. Gary-Bobo, M.; Nirdé, P.; Jeanjean, A.; Morère, A.; Garcia, M. Curr. Med. Chem. 2007, 14, 2945.

24. Jeanjean, A.; Garcia, M.; Leydet, A.; Montero, J. L.; Morère, A. Bioorg. Med. Chem. 2006, 14, 3575.

25. Vidal, S.; Garcia, M.; Montero, J. L.; Morère, A. Bioorg. Med. Chem. 2002, 10, 4051.

26. Dennis, P. A.; Rifkin, D. B. Proc. Natl. Acad. Sci. U S A 1991, 88, 580.

27. Boren, H. B.; Eklind, K.; Garegg, P. J.; Lindberg, B.; Pilotti, A. Acta Chem. Scand. 1972, 26, 4143.

28. Carretero, J. C.; Demillequand, M.; Ghosez, L. Tetrahedron 1987, 43, 5125.

29. Borbas, A.; Szabovik, G.; Antal, Z.; Herczegh, P.; Agocs, A.; Liptak, A. Tetrahedron Lett. 1999, 40, 3639.

30. Roush, W. R.; Gwaltney, S. L.; Cheng, J.; Scheidt, K. A.; McKerrow, J. H.; Hansell, E. J. Am. Chem. Soc. 1998, $120,10994$.

31. Vidil, C.; Vidal, S.; Morère, A.; Montero, J.-L. Phosphorus, Sulfur and Silicon and the Related Elements 2000, $158,125$.

32. Mahrwald, R.; Theil, F.; Schick, H.; Schwarz, S.; Palme, H.-J.; Weber, G. J. Prakt. Chem. 1986, 328, 777.

33. Ben-Bari, M.; Dewynter, G.; Aymard, C.; Jei, T.; Montero, J.-L. Phosphorus Sulfur Silicon and the Related Elements 1995, $105,129$.

34. Engel, R. Chem. Rev. 1977, 77, 349-367.

35. Hancock, M. K.; Haskins, D. J.; Sun, G.; Dahms, N. M. J. Biol. Chem. 2002, 277, 11255.

36. Purchio, A. F.; Cooper, J. A.; Brunner, A. M.; Lioubin, M. N.; Gentry, L. E.; Kovacina, K. S.; Roth, R. A.; Marquardt, H. J. Biol. Chem. 1988, 263, 14211.

37. Shah, M.; Foreman, D. M.; Ferguson, M. W. Lancet 1992, 339, 213.

38. Shah, M.; Foreman, D. M.; Ferguson, M. W. J. Cell Sci. 1994, 107, 1137. 